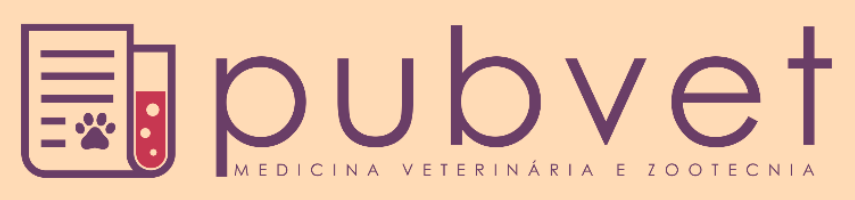

https://doi.org/10.31533/pubvet.v15n12a996.1-4

\title{
Retalho de padrão axial da artéria angular da boca para reconstrução plástica labial em cão: Relato de caso
}

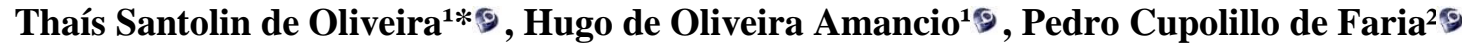 \\ ${ }^{1}$ Discente da Universidade do Grande Rio, Departamento de Medicina Veterinária. Duque de Caxias - RJ, Brasil. \\ ${ }^{2}$ Especializado em Cirurgia de Tecidos Moles de Pequenos Animais pela Anclivepa, São Paulo - SP, Brasil. \\ *Autor para correspondência, Email: thais.santolin@gmail.com
}

\begin{abstract}
Resumo. Este trabalho teve como objetivo relatar o emprego da técnica reconstrutiva do retalho de padrão axial da artéria angular da boca, após exérese cirúrgica de um tumor cutâneo localizado na região labial de um cão. Para correção do defeito facial ocasionado pela exérese, optou-se pela reconstrução plástica com a utilização do retalho, que se revelou eficiente na cicatrização da ferida cirúrgica. A realização de cirurgias reconstrutivas para reparação de defeitos cutâneos faciais é uma prática recorrente na Medicina Veterinária. Pelas características das lesões originadas, principalmente em cirurgias oncológicas e processos traumáticos, o uso de retalhos subdérmicos e de padrão axial é comumente preconizado.
\end{abstract}

Palavras-chave: Cão, cirurgia reconstrutiva, retalho, tumor

\section{Axial-pattern flap of the angular artery of the mouth for labial plastic reconstruction in a dog: Case report}

\begin{abstract}
This study aimed to report the use of the reconstructive technique of the axial flap pattern of the angular artery of the mouth, after surgical excision of a skin tumor located in the labial region of a dog. To correct the facial defect caused by excision, we opted for plastic reconstruction with the use of a flap, which proved to be efficient in healing the surgical wound. Performing reconstructive surgeries to repair facial skin defects is a recurrent practice in Veterinary Medicine. Due to the characteristics of the lesions originated, mainly in oncologic surgeries and traumatic processes, the use of subdermal and axial-pattern flaps is commonly recommended.
\end{abstract}

Keywords: Dog, reconstructive surgery, flap, tumor

\section{Colgajo de patrón axial de la arteria angular de la boca para reconstrucción plástica labial en un perro: Reporte de un caso}

Resumen. Este estudio tuvo como objetivo reportar el uso de la técnica reconstructiva del colgajo de patrón axial de la arteria angular de la boca, luego de la exéresis quirúrgica de un tumor cutáneo localizado en la región labial de un perro. Para corregir el defecto facial provocado por la exéresis, optamos por la reconstrucción plástica con el uso de un colgajo, que demostró ser eficaz en la cicatrización de la herida quirúrgica. La realización de cirugías reconstructivas para reparar los defectos de la piel del rostro es una práctica recurrente en Medicina Veterinaria. Debido a las características de las lesiones originadas, principalmente en cirugías oncológicas y procesos traumáticos, comúnmente se recomienda el uso de colgajos subdérmicos y de patrón axial.

Palabras clave: Perro, cirugía reconstructiva, colgajo, tumor 


\section{Introdução}

Lesões faciais decorrentes de processos oncológicos, anomalias congênitas e traumas podem resultar em defeitos de grandes dimensões e de difícil reparação, tornando-se frequente a realização de cirurgias reconstrutivas. Com o intuito de se garantir a máxima funcionalidade da região anatômica, a escolha da técnica empregada deve considerar a localização e tamanho do defeito, as características do tecido disponível e o suprimento sanguíneo (Pavletic, 2018).

Estas reconstruções plásticas são recorrentes pela dificuldade ou pela impossibilidade de realizar o encerramento primário da ferida cirúrgica, o qual deve garantir a ausência de linhas de tensão excessivas que comprometam a cicatrização e a vitalidade dos tecidos (Losinski et al., 2015). Sendo assim, a avaliação prévia sobre os tipos de enxertos ou retalhos possíveis para cada caso deve ser realizada, certificando-se que a região doadora apresente quantidade de pele móvel suficiente para o reparo do defeito. Ao avaliar a tensão e elasticidade das áreas envolvidas, complicações como deiscências de sutura e limitações na mobilidade podem ser evitadas (Fossum, 2014).

De acordo com os padrões de vascularização, os retalhos cutâneos podem ser classificados em pediculados ou livres e subdivididos em subdérmicos e de modelo axial. Para correção de defeitos labiais, são realizados comumente os retalhos pediculados subdérmicos ou de modelo axial (Fossum, 2014). O retalho pediculado é obtido por meio do processo de transferência de porções de derme e epiderme de um local doador para um local receptor, as quais permaneçam ligadas à região de origem por um pedículo de pele com o intuito de garantir um correto aporte sanguíneo aos tecidos. Caso a vascularização no pedículo apresente como base uma artéria e veias cutâneas diretas, este retalho é denominado de modelo axial (Pavletic, 2018).

Os retalhos de padrão axial são empregados para cobertura de áreas de grandes dimensões com contornos irregulares e apresentam taxa de sobrevivência superior aos retalhos pediculados (Fossum, 2014). São os mais aplicados para reconstrução de defeitos faciais craniais, contudo, para que se mantenha a viabilidade, é necessária a preservação da microcirculação, caso contrário, pode haver o desenvolvimento de um processo isquêmico local que conduzirá a necrose da região cirúrgica (Macphail, 2014).

Este trabalho objetivou relatar o emprego da técnica reconstrutiva do retalho de padrão axial da artéria angular da boca para reconstituição de defeito facial originado após exérese tumoral em um cão, visto que há poucas literaturas científicas disponíveis a respeito da técnica no Brasil.

\section{Relato de caso}

Foi atendido em uma clínica veterinária em Duque de Caxias, Rio de Janeiro, RJ, um cão, macho, $\mathrm{SRD}$, de cinco anos, apresentando uma massa ulcerada de cinco $\mathrm{cm}$ localizada no lábio superior direito (Figura 1.A). No primeiro atendimento clínico, foi observado um nódulo de $0,2 \mathrm{~cm}$ e sugerida a realização de biópsia; porém, a tutora não autorizou. Após dois meses, com a evolução do quadro, o animal retornou e optou-se pela exérese da neoplasia associada a cirurgia plástica reconstrutiva. $\mathrm{Na}$ avaliação pré-operatória, o paciente não apresentou alterações clínicas e laboratoriais significativas que impedissem o procedimento cirúrgico.

O retalho de padrão axial da artéria angular da boca foi a técnica de eleição para reparo do defeito devido a extensão e localização da lesão. Conforme descrito por Kirpensteijn \& Ter Haar (2019), com o paciente em decúbito lateral, foram traçadas as linhas de incisão dorsal, à margem ventral do arco zigomático, direcionando-se até a base da porção vertical do canal auditivo; e ventral, paralela ao ramo horizontal da mandíbula, a partir da borda caudal da comissura labial. Posteriormente, a linha caudal foi definida pelo aspecto lateral da primeira vértebra cervical (atlas), conectando as linhas anteriores (Figura 1.B).

A exérese foi realizada a partir de uma incisão a $3 \mathrm{~cm}$ da porção caudal e $1 \mathrm{~cm}$ da porção cranial da neoplasia, não respeitando as margens de segurança por opção da tutora, que não autorizou a ablação do coxim nasal por justificativa estética (Figura 1.C). O material removido e o linfonodo submandibular direito foram encaminhados para exame histopatológico. 
Com a demarcação, o flape foi incisado (Figura 1.D) e transposto para sítio receptor, sendo feita a aproximação das bordas cutâneas e rafia da pele com suturas em padrão simples interrompido com fios de poliglecaprone 2-0 e de Nylon 3-0, respectivamente (Figura 1.E e Figura 1.F). No sítio doador, a aposição das bordas foi realizada com suturas em padrão simples interrompido e as suturas do tecido subcutâneo em padrão simples contínuo, utilizando fio de poliglecaprone 2-0 (Figura 1.G). Por fim, a sutura em padrão Wolff, com fio de Nylon 3-0, foi escolhida para síntese cutânea deste leito (Figura 1.H)

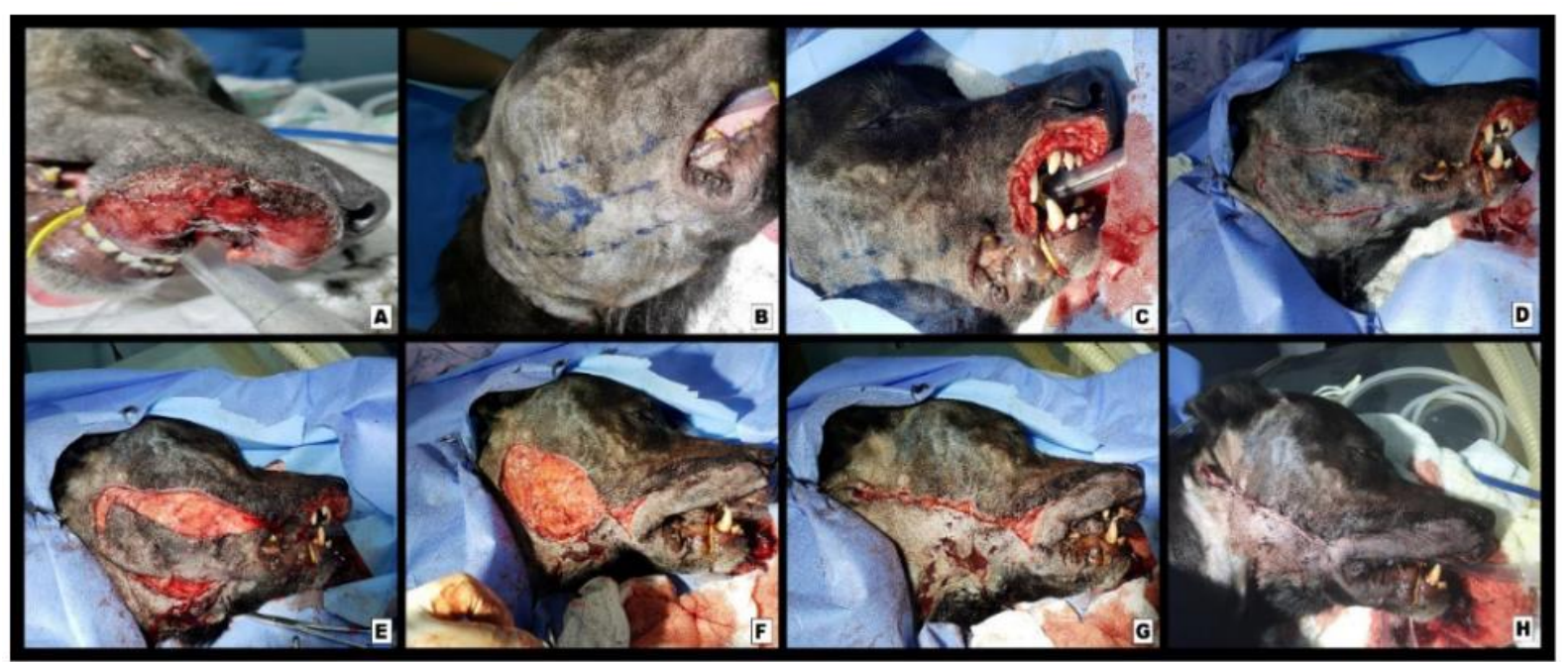

Figura 1. (A) Massa localizada em lábio superior direito. (B) Demarcação do retalho de padrão axial da artéria angular da boca. (C) Lesão ocasionada após exérese tumoral. (D) Incisão do retalho demarcado. (E) Divulsão do retalho para transposição ao sítio receptor. (F) Aproximação do tecido subcutâneo e rafia da pele no sítio receptor. (G) Aproximação do tecido subcutâneo no sítio doador. (H) Rafia da pele no sítio doador e aspecto final do procedimento cirúrgico.

No pós-operatório, optou-se pelo acompanhamento semanal para a avaliação do retalho até a retirada dos pontos. A cicatrização transcorreu sem intercorrências e foi obtido um bom resultado estético e funcional da área (Figura 2).

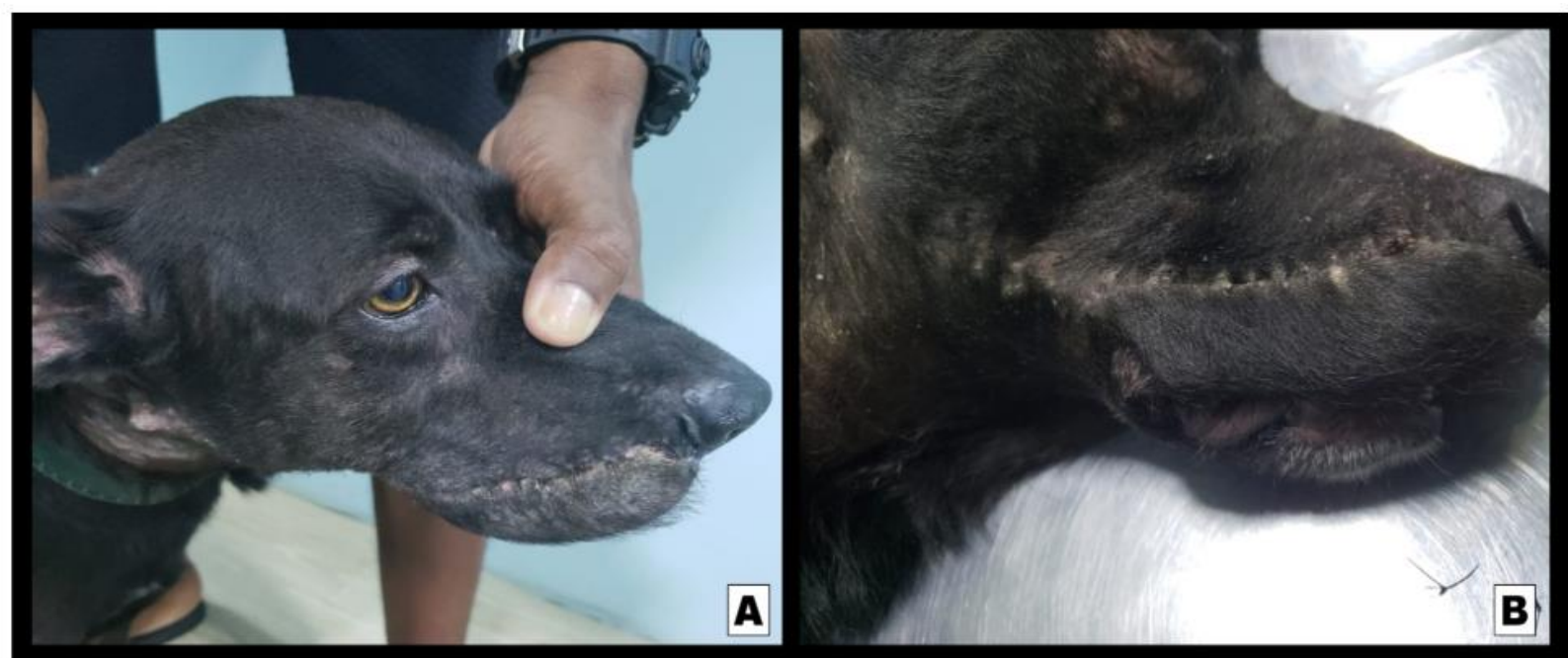

Figura 2. (A) Cicatrização após 15 dias. (B) Cicatrização após 21 dias.

\section{Discussão}

A utilização de retalhos para correção de defeitos cutâneos faciais é comum na Medicina Veterinária. Em comparação à Medicina Humana, em que usualmente são necessárias múltiplas etapas de reconstrução, as extensas regiões cutâneas doadoras, especialmente nos cães, facilitam a reparação em uma única intervenção, funcionando, portanto, como uma excelente opção (Kirpensteijn \& Ter Haar, 2019). 
A escolha do retalho dependerá das dimensões do defeito e das características do tecido, devendo fornecer um adequado aporte sanguíneo ao leito receptor. Dentre as aplicações, observa-se, com frequência, a realização de cirurgias reconstrutivas, após exérese neoplásica, para reparo cutâneo pela extensão da lesão. Nesse caso, retalhos de padrão axial, que garantem a perfusão do pedículo, a partir de ramos terminais dos vasos cutâneos diretos, são bastante empregados por apresentarem taxas de sobrevivência $50 \%$ superiores às taxas dos retalhos subdérmicos, cuja vascularização é mantida apenas pelo plexo subdérmico (Losinski et al., 2015).

Neste relato, o tratamento de eleição foi o cirúrgico pela progressão do quadro. A proximidade do retalho de modelo axial da artéria angular da boca ao defeito ocasionado pela remoção da neoplasia, facilitou a reconstituição da lesão, reduzindo o número de dissecções e rotações excessivas que comprometem o suprimento sanguíneo (Pavletic, 2018). Optou-se pelo padrão axial pela melhor condição circulatória em comparação ao retalho subdérmico, o qual poderia interferir na reparação da ferida devido a sua extensão.

A preservação de margens de segurança amplas nas exéreses tumorais é preconizada devido ao risco de recidiva local (Meuten, 2016). Contudo, no paciente relatado, embora as margens não tenham sido respeitadas, não foi constatada recidiva em pelo menos 18 meses de pós-operatório. Ademais, em relação ao aspecto funcional, nenhuma alteração foi observada e notificada pela tutora, demonstrando a eficiência do tratamento adotado.

\section{Conclusão}

A técnica reconstrutiva com a utilização do retalho de padrão axial da artéria angular da boca pode ser considerada como uma opção viável e eficiente na correção de defeitos labiais decorrentes de exéreses neoplásicas, visto que a aplicação deste retalho proporcionou um bom resultado estético e funcional.

\section{Referências bibliográficas}

Fossum, T. W. (2014). Cirurgia de pequenos animais (4th ed., Vol. 1). Elsevier Brasil.

Kirpensteijn, J., \& Ter Haar, G. (2019). Reconstructive surgery and wound management of the dog and cat. Mason Publishing Company.

Losinski, S. L., Stanley, B. J., Schallberger, S. P., Nelson, L. L., \& Millard, H. A. M. T. (2015). Versatility of the angularis oris axial pattern flap for facial reconstruction. Veterinary Surgery, 44(8), 930-938. https://doi.org/10.1111/vsu.12408.

Macphail, C. M. (2014). Surgery of the integumentary system. In T. W. Fossum (Ed.), Small animal surgery. Elsevier Editora.

Meuten, D. J. (2016). Tumors in domestic animals. John Wiley \& Sons.

Pavletic, M. M. (2018). Atlas of small animal wound management and reconstructive surgery (WileyBlackwell (ed.)). John Wiley \& Sons.

\section{Histórico do artigo:}

Recebido: 22 de julho de 2021

Aprovado: 30 de setembro de 2021

Disponível on-line: 22 de novembrode 2021
Licenciamento: Este artigo é publicado na modalidade Acesso Aberto sob a licença Creative Commons Atribuição 4.0 (CC-BY 4.0), a qual permite uso irrestrito, distribuição, reprodução em qualquer meio, desde que o autor e a fonte sejam devidamente creditados. 